\title{
Dependence of forced vital capacity manoeuvre on time course of preceding inspiration in patients with restrictive lung disease
}

\author{
N.G. Koulouris*, P. Rapakoulias*, A. Rassidakis*, J. Dimitroulis*, \\ M. Gaga*, J. Milic-Emili**, J. Jordanoglou*
}

Dependence of forced vital capacity manoeuvre on time course of preceding inspiration in patients with restrictive lung disease. N.G. Koulouris, P. Rapakoulias, A. Rassidakis, J. Dimitroulis, M. Gaga, J. Milic-Emili, J. Jordanoglou. CERS Journals Ltd 1997.

ABSTRACT: In normal subjects and patients with airway obstruction, flows during a forced vital capacity (FVC) manoeuvre are higher after a fast inspiration without an end-inspiratory pause (manoeuvre 1) as compared to a slow inspiration with an end-expiratory pause of $\sim 5 \mathrm{~s}$ (manoeuvre 2 ). In this study, we investigated the influence of these manoeuvres on maximal expiratory volume-time and flow-volume curves in patients with restrictive lung disease.

Eleven patients with restrictive lung disease were studied. Their average $( \pm \mathrm{SD})$ lung function test results were: $\mathrm{FVC}=\mathbf{5 5} \pm \mathbf{1 2} \%$ predicted value, forced expiratory volume in one second (FEV1) $52 \pm 20 \%$ pred, FEV1/FVC $85 \pm 6 \%$, total lung capacity $55 \pm 8 \%$ pred, and carbon monoxide transfer factor $47 \pm 18 \%$ pred. The patients performed the two FVC manoeuvres in random order. We compared the ensuing spirograms and maximal expiratory flow-volume curves from which peak expiratory flow, FEV1, FEV1/FVC, maximal mid-expiratory flow, and maximal flows were computed.

All spirometric indices were significantly higher with manoeuvre 1 than 2 . Maximal expiratory flows at the same lung volume were also significantly higher with manoeuvre 1 than 2 , in all patients.

Routine spirometric indices, obtained during a forced vital capacity manoeuvre depend on the time course of the preceding inspiration in patients with restrictive lung disease. Therefore, the forced vital capacity manoeuvre should be standardized if used in clinical, epidemiological and research studies.

Eur Respir J 1997; 10: 2366-2370.
*Respiratory Function Laboratory, Dept of Respiratory Medicine, University of Athens Medical School, "Sotiria" Hospital, Athens, Greece. **Meakins-Christie Laboratories, McGill University, Montreal, Quebec, Canada.

Correspondence: N.G. Koulouris Respiratory Function Laboratory Dept of Respiratory Medicine University of Athens

"Sotiria" Hospital for Diseases of the Chest 152 Mesogion Ave

Athens 11527

Athens

Greece

Keywords: Forced spirometry

forced vital capacity

lung mechanics

lung restriction

maximal expiratory flow

Received: November 151996

Accepted after revision June 191997
Previous studies have shown that in normal subjects [1-3], and patients with chronic obstructive pulmonary disease (COPD) [4] and asthma [3], the peak expiratory flow (PEF), forced expiratory volume in one second (FEV1), and maximal expiratory flow at different lung volumes (MEFx) are significantly higher if the forced vital capacity (FVC) manoeuvre is performed after a rapid lung inflation without an end-inspiratory pause (manoeuvre 1) than after a slow inspiration with a 4-6 s end-inspiratory pause (manoeuvre 2). This time dependence of the FVC manoeuvre is probably mainly caused by differences in lung recoil due to viscoelastic behaviour (stress relaxation) of the pulmonary tissue and time constant inequality within the lung [1-5]. These results dictate standardization of the inspiratory time history prior to the FVC manoeuvre.

The previous studies were performed in patients in whom the elastic recoil of the lung was normal or reduced. Since, in patients with restrictive lung disease the lung elastic recoil increases, the magnitude of the stress relaxation phenomena of their lungs should be enhanced. Therefore, in the present study, we have investigated the effect of the two aforementioned inspiratory mano- euvres prior to FVC on the maximal expiratory volumetime $(t \mathrm{FVC})$ and flow-volume (MEFV) curves in a group of patients with restrictive lung disease. The studies were performed using a pneumotachograph, as most clinical and many research laboratories conventionally use these instruments to obtain pulmonary function measurements.

\section{Materials and methods}

The subjects were 11 patients (nine males) with restrictive lung disease. Five had idiopathic pulmonary fibrosis, two sarcoidosis, two pneumoconiosis, one chronic extrinsic allergic alveolitis, and one fibrosing alveolitis secondary to systemic sclerosis. Their anthropometric characteristics are given in table 1. All patients were in a stable clinical and functional state receiving their usual medication, and were recruited from the respiratory outpatient clinic. All patients refrained from any drug on the day before testing. All had previous experience with respiratory manoeuvres and were nonsmokers. Their pulmonary function data, which were obtained in 
Table 1. - Anthropometric and routine pulmonary function data of 11 patients with restrictive lung disease

\begin{tabular}{lrr}
\hline Age yrs & 51 & $(13)$ \\
Weight kg & 74 & $(15)$ \\
Height cm & 168 & $(9)$ \\
Sex M/F & $9 / 2$ & \\
PEF \% pred & 91 & $(30)$ \\
FVC \% pred & $55(12)$ \\
FEV1 \% pred & $52(20)$ \\
FEV1/FVC \% & $85 \quad(6)$ \\
TLC \% pred & $55 \quad(8)$ \\
FRC \% pred & $62(17)$ \\
RV \% pred & $56(20)$ \\
TL,CO \% pred & $47(18)$
\end{tabular}

Values are presented as mean, and SD in parentheses. M: male; F: female; PEF: peak expiratory flow; FVC: forced vital capacity; FEV1: forced expiratory volume in one second; TLC: total lung capacity; FRC: functional residual capacity; RV: residual volume; TL,CO: transfer factor of the lungs for carbon monoxide.

the respiratory function laboratory, are shown in table 1. Forced spirometry was measured with a flow-sensing spirometer (Spiroanalyzer ST-300; Fukuda Sangyo, Tokyo, Japan). The total lung capacity (TLC) and its subdivisions were assessed by the helium dilution method, and carbon monoxide transfer factor ( $T \mathrm{~L}, \mathrm{CO})$ by the single breath-hold method (Spiroanalyzer ERS-1500; Fukuda Sangyo, Tokyo, Japan). The predicted spirometric values, static lung volumes, and TL,CO are from the European Coal and Steel Community [6]. The study had the approval of the hospital's Ethics Committee and informed consent was obtained from all patients.

During the study, flow $\left(\mathrm{V}^{\prime}\right)$ was measured at the mouth, through a heated $\left(30^{\circ} \mathrm{C}\right)$ screen pneumotachograph (Screenmate; Erich Jaeger Gmbh \& Co., Höchberg, Germany). The response of the pneumotachograph, which was calibrated at the above temperature with rotameters, was linear over the range of flows used. The calibration factor was corrected for the fall in temperature $\left(6-7^{\circ} \mathrm{C}\right)$ of the expired air on passing through the cooler pneumotachograph $[7,8]$. The flow signal was sampled at a rate of $200 \mathrm{~Hz}$, using a data acquisition system with a builtin 16-bit analogue-to-digital converter (AT-Codas; DATAQ Instruments, Inc., Akron, OH, USA) controlled by a computer (Toshiba T5200/100; Toshiba Inc., Tokyo, Japan). Volume $(V)$ was obtained by numerical integration of the flow signal after careful correction for drift. The resulting $t \mathrm{FVC}$ and MEFV curves were used for subsequent analysis. This is common practice in most lung function laboratories, though it has been pointed out that, as a result of gas compression during the FVC manoeuvre, the MEFV curves should actually be measured with a body plethysmograph $[9,10]$.

\section{Procedure}

The patients were studied seated with a nose clip on. Each patient performed two types of FVC manoeuvre: 1) after a fast inspiration (flow $>0.7 \mathrm{~L} \cdot \mathrm{s}^{-1}$ ) without an end-inspiratory pause (manoeuvre 1), and 2) after a slow inspiration (flow $<0.3 \mathrm{~L} \cdot \mathrm{s}^{-1}$ ) with an end-inspiratory pause lasting 4-6 s (manoeuvre 2). No special instructions were given by the experimenter during the performance of the manoeuvres except to urge the patients to continue hard exhalation for as long as possible. All manoeuvres were initiated from resting end-expiratory lung volume functional residual capacity (FRC). On the same day, they performed a series of such FVC manoeuvres in random order at a comfortable frequency, i.e., one every 2-3 min during 2-3 sessions lasting 5-10 min. All FVC manoeuvres chosen for subsequent analysis fulfilled the American Thoracic Society (ATS) guidelines [11].

To minimize variations of the MEFV curves [12]: 1) the first two manoeuvres were disregarded, thus making the volume history of the subsequent curves about the same $[2,4] ; 2$ ) care was taken to keep the neck at a fixed neutral position [13]; 3) each subject maintained similar duration of maximal expiratory effort [2, 4]; and 4) all subjects were studied at approximately the same time of day [12].

To characterize the manoeuvres for each test, the following variables were assessed: 1) the expiratory reserve volume (ERV) from which inspiration started; 2) the duration of inspiration $(t \mathrm{I}) ; 3$ ) the mean inspiratory flow $(V \mathrm{~T} / t \mathrm{I})$; and 4$)$ the duration of end-inspiratory pause $(t \mathrm{p})$. The variables characterizing the two manoeuvres are presented in table 2 .

For both manoeuvres, at least three FVC curves were obtained that fulfilled the ATS criteria [11]. The largest FVC and FEV1 values were recorded after examining the data from all the acceptable curves, even if they did not come from the same curve. The highest instantaneous flows (PEF, maximal expiratory flow at 75, 50 and 25\% of FVC (MEF75, MEF50 and MEF25, respectively) and forced expiratory flow between $25 \%$ and $75 \%$ of FVC (MMEF)) were measured from the single curve that met the acceptability criteria and exhibited the largest sum of FVC plus FEV1 ("best" test) [11].

\section{Statistical analysis}

Values are reported as mean $( \pm \mathrm{SD})$. The average values of the various variables were compared using the paired student t-test. A p-value of less than 0.05 was taken as statistically significant. Linear regression analysis was performed using the least squares technique.

Table 2. - Variables characterizing the two types of forced vital capacity manoeuvre

\begin{tabular}{lcc}
\hline & $\begin{array}{c}\text { Manoeuvre 1 } \\
\text { Fast }\end{array}$ & $\begin{array}{c}\text { Manoeuvre 2 } \\
\text { Slow }\end{array}$ \\
\hline $\mathrm{ERV} \mathrm{L}$ & $0.82(0.3)$ & $0.79(0.3)$ \\
$t \mathrm{I} \mathrm{S}$ & $0.83(0.3)$ & $4.69(1.7)$ \\
$V \mathrm{~T} / t \mathrm{I} \quad \mathrm{L} \cdot \mathrm{s}^{-1}$ & $1.96(0.79)$ & $0.27(0.14)$ \\
$t \mathrm{p} \mathrm{S}$ & $0.11(0.19)$ & $4.34(0.72)$ \\
$t \mathrm{E} \mathrm{S}$ & $5.89(0.67)$ & $6.12(0.31)$ \\
\hline
\end{tabular}

Values are presented as mean, and SD in parentheses. ERV: expiratory reserve volume from which inspiration started; $t \mathrm{I}$ : duration of inspiration; $V \mathrm{~T} / \mathrm{t} \mathrm{I}$ : mean inspiratory flow; $t_{\mathrm{p}}$ : duration of end-inspiratory pause; $t \mathrm{E}$ : duration of expiratory effort; there was no significant difference in ERV and $t \mathrm{E}$ between manoeuvres 1 and 2 . 


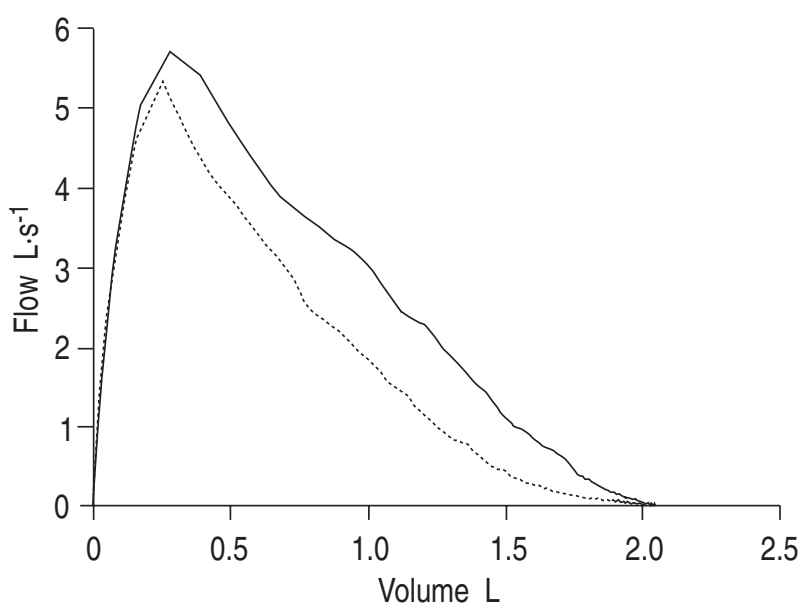

Fig. 1. - Representative flow-volume curves obtained from a patient with manoeuvre 1 (fast; —_ ) and manoeuvre 2 (slow; ………......).

\section{Results}

Figure 1 shows the fast (manoeuvre 1) and slow (manoeuvre 2) MEFV curves obtained in a patient. During manoeuvre 1 the flows were higher than during manoeuvre 2. The mean values of PEF, FEV1, FEV1/FVC, MMEF, MEF25, MEF50 and MEF75 of the 11 patients were significantly higher with manoeuvre 1 than 2 (table 3 , figs. 2 and 3). In almost all instances the values of these variables were higher with manoeuvre 1 than 2 (figs. 2 and 3). Only one patient had a higher ratio of FEV1/FVC with manoeuvre 2 than 1 .

There was no significant correlation between the percentage change of PEF, FEV1, and MMEF obtained with the two different manoeuvres and FVC, TLC, FEV1 of predicted value, or FEV1/FVC, residual volume (RV)/ TLC, FRC/TLC(\%), and TL,CO \% pred.

\section{Discussion}

In the present study we found that, in patients with restrictive lung disease, the values of PEF, FEV1, and maximal flows were significantly higher with manoeuvre 1 (rapid inspiration without end-inspiratory pause) than with manoeuvre 2 (slow inspiration with end-inspiratory pause). This has not been reported previously for patients with restrictive lung disease. Similar results

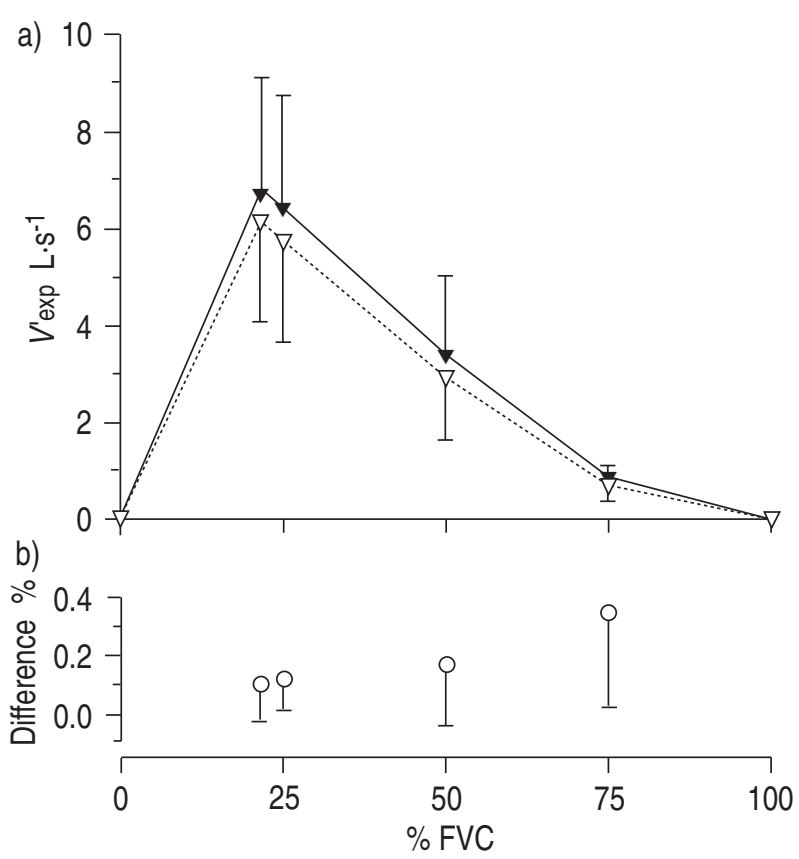

Fig. 2. - a) Mean ( \pm SD) values of expiratory flow ( $\left.V^{\prime} \exp \right)$ at different lung volumes (percentage of forced vital capacity $(\% \mathrm{FVC})$ ) in 11 patients during manoeuvre 1 (fast; $\boldsymbol{\nabla})$ and 2 (slow; $\nabla$ ). b): difference in flow between manoeuvres 1 and 2, expressed as a percentage of flow with manoeuvre 2 in the 11 patients at different lung volumes.

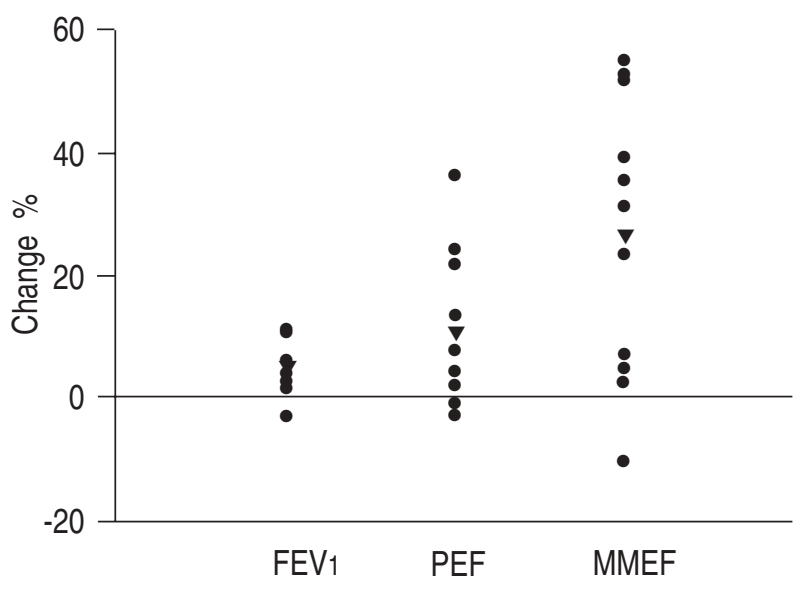

Fig. 3. - Individual $(\bullet)$ and mean $(\boldsymbol{\nabla})$ values of changes (fastslow/slow) in FEV1, PEF, and MMEF of the 11 patients. For further definitions see table 3 .
Table 3. - Spirometric indices obtained during manoeuvres 1 (fast) and 2 (slow)

\begin{tabular}{|c|c|c|c|c|}
\hline & $\begin{array}{c}\text { Manoeuvre } 1 \\
\text { Fast }\end{array}$ & $\begin{array}{l}\text { Manoeuvre } 2 \\
\text { Slow }\end{array}$ & $\begin{array}{c}\text { Difference } \\
\text { (fast/slow)/slow } \\
\%\end{array}$ & p-value \\
\hline $\mathrm{PEF} \quad \mathrm{L} \cdot \mathrm{s}^{-1}$ & $6.6 \quad(2.2)$ & $5.9 \quad(2)$ & 11 (12) & 0.016 \\
\hline FVC L & $2.20(0.85)$ & $2.18(0.86)$ & $1.4(3)$ & NS \\
\hline FEV1 L & $1.9 \quad(0.7)$ & $1.8 \quad(0.7)$ & $6 \quad(5)$ & 0.008 \\
\hline $\mathrm{FEV}_{1} / \mathrm{FVC} \%$ & 86 & (5) & (4) & 0.006 \\
\hline MMEF $\quad \mathrm{L} \cdot \mathrm{s}^{-1}$ & $2.5 \quad(0.9)$ & $(0.8)$ & $27 \quad(23)$ & 0.007 \\
\hline MEF75 L $\cdot \mathrm{s}^{-1}$ & $6.2(2.2)$ & $5.4 \quad(2)$ & 14 (12) & 0.002 \\
\hline MEF50 L $\cdot \mathrm{s}^{-1}$ & 3.4 (1.5) & $2.8 \quad(1.2)$ & $24 \quad(25)$ & 0.036 \\
\hline $\mathrm{MEF}_{25} \mathrm{~L} \cdot \mathrm{s}^{-1}$ & $0.9 \quad(0.3)$ & $0.7 \quad(0.3)$ & 32 (27) & 0.001 \\
\hline
\end{tabular}

Values are presented as mean, and SD in parentheses. PEF: peak expiratory flow; FVC: forced vital capacity; FEV1: forced expiratory volume in one second; MMEF: forced expiratory flow between $25 \%$ and $75 \%$ of FVC. MEF25, MEF50 and MEF75: maximal expiratory flow at $25 \%, 50 \%$ and $75 \%$ of FVC, respectively. have been found in normal adults $[1,2]$, COPD [4], and patients with asthma [3].

On average, the absolute difference in PEF between manoeuvres 1 and 2 was similar to that found in COPD but lower than in asthmatic patients and normal subjects (table 4). However, when change in PEF ( $\triangle \mathrm{PEF})$ was expressed as a percentage during the slow manoeuvre (PEFslow), the changes in the restrictive patients were close to those of normals and asthmatics, but markedly lower than in COPD. Similar results were also found in terms of change in FEV1 $(\triangle \mathrm{FEV} 1)$ expressed as a percentage of FEV1 during the slow manoeuvre (table 4). 
Table 4. - Average differences $(\Delta)$ of peak expiratory flow (PEF) and forced expiratory volume in one second (FEV 1$)$ between manoeuvres 1 and 2 in normal subjects, chronic obstructive pulmonary disease (COPD), asthmatics and patients with lung restriction

\begin{tabular}{lrccccc}
\hline Subjects & {$[$ Ref $]$} & $\begin{array}{c}\Delta \mathrm{PEF} \\
\mathrm{L} \cdot \mathrm{s}^{-1}\end{array}$ & $\begin{array}{c}\Delta \mathrm{PEF} / \text { slow } \\
\%\end{array}$ & $\begin{array}{c}\Delta \mathrm{FEV} 1 \\
\mathrm{~L}\end{array}$ & $\begin{array}{c}\Delta \mathrm{FEV} \text { 1/slow } \\
\%\end{array}$ \\
\hline Normals & 13 & {$[2]$} & 1.28 & 15 & 0.19 & 5 \\
Normals & 7 & {$[3]$} & 0.83 & 8 & 0.02 & 1 \\
COPD & 13 & {$[4]$} & 0.71 & 30 & 0.24 & 23 \\
Asthma & 8 & {$[3]$} & 1.12 & 15 & 0.17 & 7 \\
Lung & 11 & $\begin{array}{c}\text { Present } \\
\text { study }\end{array}$ & 0.70 & 11 & 0.10 & 6 \\
restriction & & & & &
\end{tabular}

The fact that the values of $\triangle \mathrm{PEF} / \mathrm{PEF}$ from the slow manoeuvre and $\triangle \mathrm{FEV} 1 / \mathrm{FEV} 1$ from the slow manoeuvre found in the patients with restrictive lung disease were similar to those of normal subjects can probably be explained as follows. Though in patients with restrictive lung disease there is an increase in static elastic recoil pressure of the lung $(P \mathrm{el}, \mathrm{st}, \mathrm{L})$ at any given thoracic gas volume, their static $P$ - $V$ curves, normalized by plotting $P$ el,st,L against percentage vital capacity $(\% \mathrm{VC})$, are in general close to normal. If the viscoelastic properties of the lung are also normal at any given lung volume expressed as \%VC, one would expect a normal decrease in lung elastic recoil, and hence in maximal flow ( $\left.V^{\prime} \max \right)$ between the fast and slow FVC manoeuvres, in patients with restrictive lung disease.

There are several mechanisms that could explain the higher values of PEF, FEV1, MMEF and MEF25, MEF50 and MEF75 observed in our patients with manoeuvre 1 relative to 2 :

1) Differences in TLC. This is an unlikely mechanism as the values of FVC and ERV were essentially the same in the two manoeuvres (table 2 and 3), indicating that the patients inspired to the same TLC. In addition, care was taken with manoeuvre 2 to maintain a constant lung volume during breath holding at TLC.

2) Differences in expiratory effort. In the present study there was no direct or indirect measurement of expiratory effort. It is possible that part of the differences in $\mathrm{PEF}$ and flows in the early effort-dependent part of the FVC curve was due to greater activation of expiratory muscles [2-4]. MMEF and instantaneous flows are also effort dependent. However, if the expiratory efforts were higher during manoeuvre 1 than 2, the values of MMEF and other flows should be lower with manoeuvre 1 as a result of greater thoracic gas compression. In contrast, our data support the notion that the opposite is true (table 3 ). In addition, although FEV1 is much less dependent on effort than had been originally thought [14], provided that the FVC manoeuvre fulfils the ATS criteria $[15,16]$, it is also significantly different. Consequently, while the increase in PEF could, in part, be related to greater expiratory muscle activation, muscle activation alone is unlikely to explain the higher FEV1, MMEF, and MEF25, MEF50 and MEF75 found with manoeuvre 1 [2-4].

3) Time constant inequality within the lungs. With manoeuvre 1 the fast units of the lung should be preferentially filled and the expiratory flow would be expected to be higher than with 2 , whilst the long inspiratory pause may cause volume redistribution towards the slow units [5]. However, the differences in PEF and FEV1 persisted after administration of a bronchodilator (salbutamol) in the asthmatic patients $[3,17]$. This suggests that the time dependency of these parameters is not due to time constant inequality and bronchomotor tone, but rather to global loss in elastic recoil during the breath hold at TLC $[2-4,17]$, reflecting the stress relaxation properties of the respiratory system $[18,19]$. It should be noted that while the changes in elastic recoil pressure of the chest wall $(P \mathrm{el}, \mathrm{w})$ between manoeuvres 1 and 2 should affect the flow only during the early effort-dependent part of FVC, the concomitant changes in $P$ el,L should affect the flow at all lung volumes. Indeed, according to a simple model $[18,19]$ that can mimic to some degree the mechanical behaviour of the respiratory system, the elastic recoil pressure of the respiratory system during a forced exhalation should be higher with the fast than the slow manoeuvre.

4) Gas compression artifacts. In line with everyday practice and numerous previous studies, volume was obtained by integration of the flow signal, and therefore the MEFV curves were based on spirometric FVC. Differences in thoracic gas compression may explain, at least in part, the differences between the manoeuvres. To avoid such errors, volume should have been measured with a body plethysmograph [9, 10]. However, time dependency of FVC manoeuvres were also observed in previous studies $[2,4]$ in which volume was assessed plethysmographically.

The difference in gas composition during manoeuvres 1 and 2 in exhaled air may have negligible impact on our data as FVC is similar between the fast and slow manoeuvres [20] (table 3).

Changes in balance between airway and parenchymal hysteresis may not substantially contribute to the reported differences in flows and volumes since $P$ el,L appears to be the only factor of paramount importance.

In conclusion, the present data indicate that in patients with restrictive lung disease, dynamic lung volumes and maximum flows during the forced vital capacity manoeuvre depend on the pattern of the preceding inspiration. Thus, the forced expiratory spirogram and the maximal expiratory flow volume curve are not single fixed curves, but rather there is a family of different curves which are time-dependent $[2-4,17]$, This observation is clinically important because if measurement of the highest potential flow is desired, then a fast inspiration to total lung capacity without an end-inspiratory pause (manoeuvre 1) should be used. In addition, when comparing serial data in an individual patient, it is imperative that the same approach be used $[6,11,12]$. These results clearly dictate that the inspiratory manoeuvre prior to forced vital capacity must be standardized.

\section{References}

1. Higenbottom T, Clark TJH. Influence of breath holding at total lung capacity on maximal expiratory flow measurements. Clin Sci 1981; 60: 11-15.

2. D'Angelo E, Prandi E, Milic-Emili J. Dependence of maximal flow-volume curves on time course of preceding inspiration. J Appl Physiol 1993; 75: 1155-1159. 
3. Wanger JS, Ikle DN, Cherniack RM. The effect of inspiratory maneuvers on expiratory flow rates in health and asthma: influence of lung elastic recoil. Am J Respir Crit Care Med 1996; 153: 1302-1308.

4. D' Angelo E, Prandi E, Marazzini L, Milic-Emili J. Dependence of maximal flow-volume curves on time course of preceding inspiration in patients with chronic obstruction pulmonary disease. Am J Respir Crit Care Med 1994; 150: 1581-1586.

5. Melissinos CG, Webster P, Tien YK, Mead J. Time dependence of maximum flow as an index of nonuniform emptying. J Appl Physiol 1979; 47: 1043-1050.

6. Quanjer $\mathrm{PhH}$, ed. Standardized lung function testing. Report Working Party "Standardization of Lung Function Tests", European Community for Coal and Steel. Eur Respir J 1993; 6 (Suppl. 16): 1-100.

7. Miller MR, Sigsgaard T. Prevention of thermal and condensation errors in pneumotachographic recordings of the maximal forced expiratory manoeuvre. Eur Respir J 1994; 7: 198-201.

8. Wanger J. Pulmonary Function Testing. A Practical Approach. Baltimore, MD, USA. Williams \& Wilkins, 1992.

9. Jaeger MJ, Otis AB. Effects of compressibility of alveolar gas on dynamics and work of breathing. J Appl Physiol 1964; 19: 83-91.

10. Ingram RH Jr, Schilder DP. Effect of gas compression on pulmonary pressure, flow, and volume relationship. J Appl Physiol 1966; 21: 1821-1826.

11. American Thoracic Society. Standardization of spirometry - 1994 update. Am J Respir Med 1995; 152: $1107-1136$.
12. American Thoracic Society. Lung function testing: selection of reference values and interpretative strategies. Am Rev Respir Dis 1991; 144: 1202-1218.

13. Melissinos CG, Mead J. Maximum expiratory flow changes induced by longitudinal tension of trachea in normal subjects. J Appl Physiol 1977; 43: 537-544.

14. Krowka MJ, Enright PL, Rodarte JR, Hyatt RE. Effect of effort on measurement of forced expiratory volume in one second. Am Rev Respir Dis 1987; 136: 829_ 833.

15. Coates AL, Allen PD, Desmond KJ, Demizio DL. Sources of variation in FEV1. Am J Respir Crit Care Med 1994; 149: 439-443.

16. Park SS. Effect of effort versus volume on forced expiratory flow measurement. Am Rev Respir Dis 1988; 138: 1002-1005.

17. D'Angelo E, Milic-Emili J, Marazzini L. Effects of bronchomotor tone and gas density on time dependence of forced expiratory vital capacity maneuver. Am J Respir Crit Care Med 1996; 154: 1318-1322.

18. D'Angelo E, Robatto FM, Calderini E, et al. Pulmonary and chest wall mechanics in anesthetized paralysed humans. J Appl Physiol 1991; 70: 2602-2610.

19. Milic-Emili J, D'Angelo E. Effects of viscoelastic properties of respiratory system on respiratory dynamics. In: Control of Breathing and Its Modelling Perspective. Honda Y, et al., eds., Plenum Press, New York, 1992, pp. 341-345.

20. Degroodt EG, Quanjer PH, Wise ME. Influence of external resistance and minor flow variations on single breath nitrogen test and residual volume. Bull Europ Physiopath Resp 1983; 19: 267-272. 